\title{
MULHERES REFUGIADAS E VULNERABILIDADE: A DIMENSÃO DA VIOLÊNCIA DE GÊNERO EM SITUAÇÕES DE REFÚGIO E AS ESTRATÉGIAS DO ACNUR NO COMBATE A ESSA VIOLÊNCIA
}

\author{
Simone Andrea Schwinn ${ }^{1}$ \\ Marli Marlene Moraes da Costa ${ }^{2}$
}

\begin{abstract}
Resumo: As migraçóes internacionais são uma realidade cada vez mais importante nos debates que envolvem direitos humanos e de forma transversal, sobre os direitos humanos das mulheres, cujas pesquisas ainda são restritas. Segundo o ACNUR - Agência das Naçóes Unidas para Refugiados - as mulheres e crianças representam, ao menos, metade das pessoas deslocadas no mundo, encontrandose em situação de vulnerabilidade, longe de suas origens, sem a proteção de seu governo, afastadas da família. Nesse contexto, as mulheres e meninas, na longa jornada em busca de segurança, sofrem com a indiferença oficial, a perseguição e, não raro, com abusos sexuais e a consequente estigmatizaçáo por sua condiçáo de mulher refugiada. Os conflitos armados tem sido causa frequente para o grande deslocamento de pessoas, e, para as mulheres, estas situações representam um risco muito maior, uma vez que em muitos casos o estupro tem sido usado como arma de guerra. Observa-se entáo, as diferentes dimensôes que a violência alcança na vida das mulheres refugiadas: cultural, social, psicológica, sexual. As estratégias para combate às estas formas de violência tem sido alvo de atençáo
\end{abstract}

1 Doutoranda em Direito pelo PPGD da Universidade de Santa Cruz do Sul-UNISC, Área de concentração Direitos Sociais e Políticas Públicas, linha de pesquisa Diversidade e Políticas Públicas, com Bolsa PROSUP/CAPES. Mestra em Direito pelo mesmo programa na linha de pesquisa Constitucionalismo Contemporâneo, com Bolsa CNPq. Integrante dos grupos de Pesquisa "Direito, Cidadania e Políticas Públicas", coordenado pela Prof ${ }^{a}$ Pós Dra. Marli M. M. da Costa vinculado ao PPGD da Unisc. Integrante do Grupo de Pesquisa Ciência Penal Contemporânea, coordenado pelo Prof. Dr. Tupinambá Pinto de Azevedo, da Universidade Federal do Rio Grande do Sul-UFRGS. Integrante da Cátedra Sérgio Vieira de Mello da UFRG e do MIPESUL- Núcleo de Pesquisas em Migrações da Região Sul. E-mail: ssimoneandrea@gmail.com.

2 Pós-Doutora em Direito pela Universidade de Burgos/Espanha, com Bolsa CAPES. Doutora em Direito pela Universidade Federal de Santa Catarina-UFSC. Coordenadora do Programa de Pós-graduação em Direito - Mestrado e Doutorado - na Universidade de Santa Cruz do SulUNISC. Coordenadora do Grupo de Estudos e Pesquisa "Direito, Cidadania e Políticas Públicas" do Programa de Pós-graduação em Direito- Mestrado e Doutorado- da Universidade de Santa Cruz do Sul-UNISC, certificado pelo CNPq. Professora da Graduação em Direito da FEMAFundação Educacional Machado de Assis de Santa Rosa/RS. Psicóloga com especialização em terapia familiar. Integrante do MIPESUL- Núcleo de Pesquisas em Migrações da Região Sul. E-mail:marlicosta15@yahoo.com.br. 
do ACNUR, que tem procurado promover formas de proteção a partir de compromissos assumidos pelo Alto Comissariado, no sentido de atender as especificidades e necessidades de proteçáo dessa populaçáo vitimada, muitas vezes, pela indiferença estatal. Para descrever esta jornada, necessário entender o fenômeno das migraçôes, e, de forma especial o refúgio, para que se possa dar atenção às dimensôes da violência sofrida por mulheres refugiadas, condição que lhes coloca em situação de extrema vulnerabilidade. $\mathrm{Na}$ condição de refugiadas, fazem jus à proteçâo pelo Alto Comissariado das Naçóes Unidas para Refugiados que, na tentativa de combater as graves violaçóes sofridas por mulheres e meninas em situação de refúgio criou mecanismos específicos para esta população. Entende-se que, embora importante, o trabalho do ACNUR tem sido insuficiente para o combate às diferentes formas de violência por elas sofridas. Ressalta-se que se trata de um trabalho de revisáo bibliográfica, baseado em literatura relevante sobre o tema, além de pesquisa documental. O método a ser utilizado é o dedutivo, cuja hipótese reside no fato de que a violência sofrida por mulheres refugiadas tem várias dimensôes, nem sempre alcançadas pelas instituições responsáveis por sua proteção, mostrando que tem sido insuficiente para sanar essas violências.

Palavras-chave: ACNUR. Gênero. Migrações. Refúgio. Violência.

\begin{abstract}
International migration is an increasingly important reality in discussions involving human rights and transversely on the human rights of women, whose research is restricted. According to the United Nations Agency for Refugees - UNHCR - women and children represent at least half of the displaced people in the world, finding themselves in vulnerable situations, far from their origins, without the protection of his government, away from family. In this context, women and girls, in the long journey to safety, suffering with official indifference, persecution and often with sexual abuse and the consequent stigmatization by their condition of refugee women. Armed conflicts have been frequent cause for the large displacement of people, and, for women, these situations represent a much higher risk, since in many cases rape has been used as a weapon of war. It is observed then the different dimensions that violence reaches the lives of refugee women: cultural, social, psychological and sexual. Strategies to combat such violence has been UNHCR's attention target, which has sought to promote forms of protection from commitments made by the High Commissioner, specifically to meet the specific and protection needs that victimized population, often by state indifference. To describe this journey, necessary to understand the phenomenon of migration, and in a special way the refuge, so you can give attention to the dimensions of the violence suffered by refugee women, a condition that puts them in situations of extreme vulnerability. In refugee status, are entitled to protection by the United Nations High Commissioner for Refugees that, in an attempt to combat the serious violations suffered by women and girls in refugee situation has created specific mechanisms for this population. It is understood that, while important, UNHCR's work has been insufficient to combat the various forms of violence they suffered. It is emphasized that this is a literature review work, based on relevant literature on the subject, as well as desk research. The method to be used is the deductive hypothetical, whose hypothesis lies in the fact that the violence suffered by refugee women has several dimensions, not always achieved by the institutions responsible for their protection, showing that it has been insufficient to remedy such violence.
\end{abstract}

Keywords: Gender. Refugee. Migrations. UNHCR. 
Que coisa estranha,

que coisa esquisita deve ser:

largar o país, a língua, abandonar a família em direção a algo completamente novo, sobretudo, incerto.

Tatiana Salem Levy

A chave da casa

\section{Introduçáo}

Em 2016, várias foram as manchetes denunciando a violência de gênero sofrida por mulheres e meninas refugiadas: "Mulheres e crianças são estupradas como forma de "pagar" entrada na Europa" (PRAGMATISMO POLÍTICO, 28 de janeiro de 2016); "Mulheres refugiadas que se deslocam pela Europa estão correndo riscos, afirma a ONU" (ACNUR, 26 de janeiro de 2016); "Mulheres refugiadas relatam estupro em troca de abrigo na Europa" (FÓRUM, 27 de janeiro de 2016); "Refugiadas sofrem violência sexual em êxodo, diz Anistia Internacional" (G1, 18 de janeiro de 2016); "Mulheres e crianças já são 2/3 dos refugiados e representam grupo mais vulnerável à violência"(JORNAL MULIER, 27 de junho de 2016), e assim outras tantas manchetes poderiam aqui ser reproduzidas.

Historicamente, uma das manifestações mais evidentes da desigualdade de gênero é a violência contra as mulheres. Em um contexto migratório, não voluntário, como é o caso de refúgio, onde um grande contingente de pessoas se desloca fugindo justamente da violência, esse tipo de violência acaba potencializada. Mulheres e crianças acabam sendo os grupos mais vulneráveis.

No intuito de analisar as dimensões da violência de gênero sofrida por mulheres em situação de refúgio, e as estratégias do Alto Comissariado das Nações Unidas para Refugiados-ACNUR para combate a essa violência, é que se propõe este trabalho. Para tanto, primeiramente, se procederá à distinção entre migrantes e refugiados, na medida em que as duas condições contam com sistemas de proteção diferenciados, do ponto de vista social e jurídico.

Posteriormente, abordará as dimensões da violência em situações de refúgio, tendo em vista a situação de vulnerabilidade proporcionada por essa condição e, onde se sobressai a violência sexual e de gênero. Por fim, tratará das estratégias do Alto Comissariado das Nações Unidas-ACNUR para combate à violência de gênero sofrida por mulheres refugiadas.

Trata-se de um trabalho de revisão bibliográfica, baseado em literatura relevante sobre o tema, além de pesquisa documental. O método a ser utilizado é o hipotético dedutivo, cuja hipótese reside no fato de que a violência sofrida por mulheres refugiadas tem várias dimensões, nem sempre alcançadas pelas instituições responsáveis por sua proteção, mostrando que tem sido insuficiente para sanar essas violências. 


\section{Sobre migraçóes e refúgio: quem é migrante e quem é refugiado?}

De maneira geral, pode-se caracterizar a migração enquanto o movimento de uma pessoa ou grupo de pessoas de um território a outro, cruzando uma fronteira administrativa ou política com intenção de estabelecer-se de maneira indefinida ou temporal em um lugar distinto de suas nações.

Essa migração pode ser voluntária ${ }^{3}$ ou forçada. No segundo caso, trata-se de alguém que temendo ser perseguido por motivos de raça, religião, nacionalidade, grupo social ou opiniões políticas, se encontra fora do país de sua nacionalidade e que não pode ou, em virtude desse temor, não quer valer-se da proteção desse país. Essa definição encontra-se na Convenção das Nações Unidas sobre o Estatuto dos Refugiados, ou Convenção de $1951^{4}$.

Ressalta-se ainda que para o reconhecimento de um indivíduo enquanto refugiado, além dos critérios objetivos trazidos pela Convenção de 1951, são necessários também critérios subjetivos como o fundado temor de perseguição. Além disso, o solicitante de refúgio deve encontrar-se fora de seu país de origem, não podendo para ele retornar.

A proteção aos perseguidos em razão de raça, nacionalidade, opinião política, religião ou grupo social pode ser considerada um costume internacional, mas é somente com sua inserção na Declaração Universal dos Direitos Humanos de 1948, que o asilo ${ }^{5}$ passa a ser juridicamente reconhecido ${ }^{6}$. Em um retrospecto histórico, é possível afirmar que a evolução do Direito Internacional, em especial no que diz respeito aos direitos humanos, tem caminhado no sentido de agregar o maior número possível de indivíduos carentes de proteção. Assim, o Direito

3 Poder-se-ia questionar se o ato de migrar fugindo da fome e das condições precárias em relação ao trabalho e políticas assistenciais é realmente voluntário. Mas, no âmbito da proteção internacional aos migrantes, este grupo se enquadra enquanto migrante econômico e não refugiado.

4 A Resolução 429 V da Assembleia Geral das Nações Unidas, em 1950, convocou em Genebra, em 1951, uma Conferência de Plenipotenciários das Nações Unidas para redigir uma convenção regulatório do status legal dos refugiados, que teve como resultado a Convenção das Nações Unidas sobre o Estatuto dos Refugiados, adotada em 28 de julho de 1951, tendo entrado em vigor em 22 de abril de 1954. De acordo com o Acnur: "A Convenção consolida prévios instrumentos legais internacionais relativos aos refugiados e fornece a mais compreensiva codificação dos direitos dos refugiados a nível internacional. Ela estabelece padrões básicos para o tratamento de refugiados - sem, no entanto, impor limites para que os Estados possam desenvolver esse tratamento" (ACNUR, online).

5 Na América Latina, asilo e refúgio são situações jurídicas distintas: o asilo é concedido aos perseguidos políticos, e o refúgio às demais formas de perseguição elencadas pela Convenção de 1951. Na Europa e Estados Unidos, todas as situações que se enquadram como "refúgio", são denominadas "asilo", sem a distinção de tratamento dada pela América Latina.

6 Artigo XIV. 1.Toda pessoa, vítima de perseguição, tem o direito de procurar e de gozar asilo em outros países. 2. Este direito não pode ser invocado em caso de perseguição legitimamente motivada por crimes de direito comum ou por atos contrários aos propósitos e princípios das Nações Unidas (DECLARAÇÃO UNIVERSAL DOS DIREITOS HUMANOS). 
Internacional dos Refugiados surge de uma visão atualizada de direitos humanos, cuja compreensão "parte da esfera de direitos da pessoa humana" (LIPPSTEIN; GOMES, 2013, p. 158).

De acordo com o Instituto de Migrações e Direitos Humanos-IMDH (2014) a migração não é um fenômeno novo, mas que historicamente, se repete com frequência e intensidade variadas. "Os grandes movimentos migratórios ocorridos em outras épocas tiveram sua causa nas invasões, conquistas, êxodos, mudanças sazonais, fome, superpopulação de determinadas regiões, entre outras". Atualmente, tais motivos são agravados pela globalização, a demografia de determinados países ou regiões, a violação de direitos, desemprego, perseguições, discriminação, xenofobia, a desigualdade econômica entre as diferentes regiões globais, a violência e as catástrofes naturais, para citar algumas causas.

Relatório das Nações Unidas, publicado em 2016, informa que desde o ano 2000 até 2015 , o número de migrantes internacionais cresceu $41 \%$, totalizando 244 milhões de pessoas em deslocamento em todo o mundo. Destes, mais de 15 milhões são refugiados (ONU BRASIL, 2016) e, ao contrário do que costuma ser reproduzido, tanto pela mídia, quanto por autoridades de países europeus, o maior contingente de pessoas refugiadas tem como destino a África, a Ásia e o Pacífico, como mostra o gráfico a seguir:

Gráfico 1: Principais regiões de destino dos refugiados

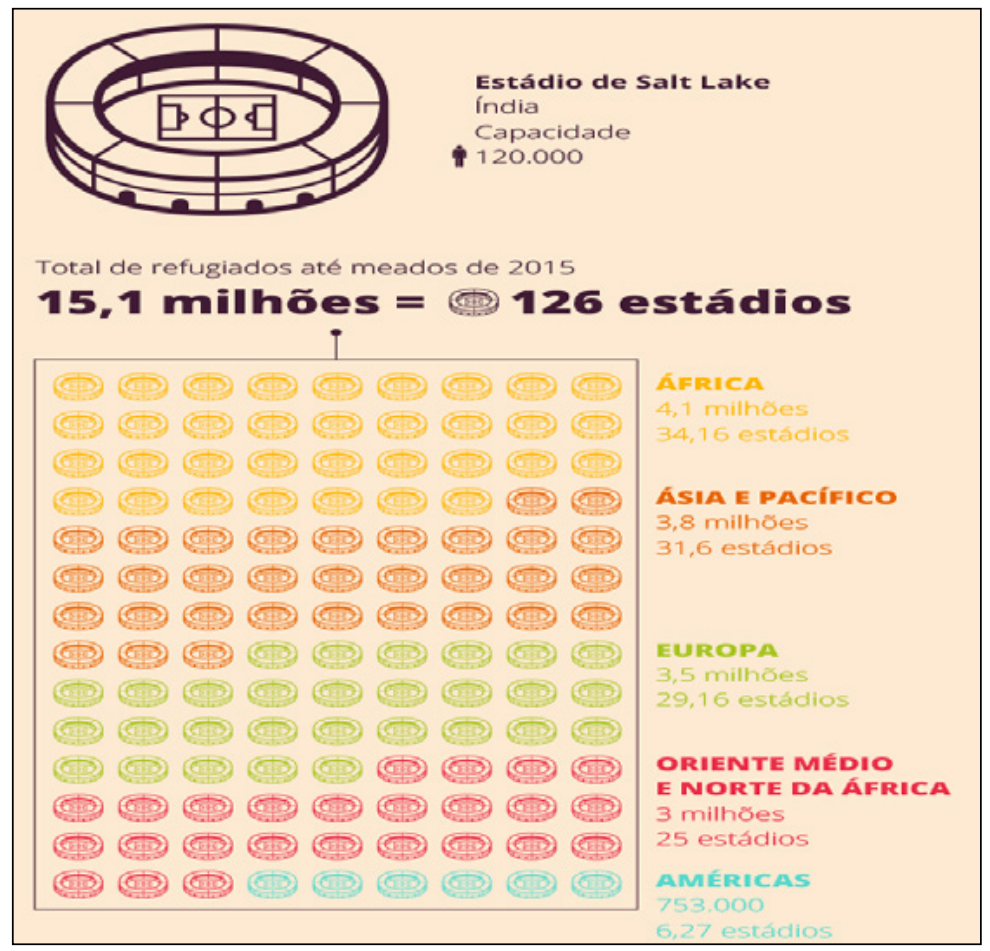

Fonte: SUR. Revista Internacional de Direitos Humanos. Infográficos Migrações e Direitos Humanos. Disponível em: < http://sur.conectas.org/infograficos-migracao/>. Acesso em: 29 jul 2016. 
Os Objetivos de Desenvolvimento Sustentável (ODS) estabelecidos pela ONU destacam que a vulnerabilidade dos migrantes, deslocados internos e refugiados, relacionada ao deslocamento forçado e crises humanitárias, pode reverter os avanços das últimas décadas. Entre os compromissos da Agenda de 2030 está o de proteger os direitos dos migrantes e implementar políticas de migração (ONU BRASIL, 2016).

Winckler (2001, p. 121), observa que esses migrantes são "pessoas deslocadas", que muitas vezes, devido à sua condição, "não encontram um lugar no mundo onde possam existir dignamente. Não possuem um status político que lhes possibilite ser tratados pelos demais como semelhantes." Isso demonstra a complexidade de um fenômeno com diversas implicações, seja para aqueles que se deslocam, seja para os países que os recebem.

E nesse percurso da fuga pela sobrevivência, muitos não chegam ao seu destino: a Organização Internacional de Migração - IOM (sigla em inglês), estima que em 2015, mais de duas mil pessoas morreram no mar Mediterrâneo tentando chegar à Europa. O Número de mortes é menor do que o registrado no ano anterior, devido às ações de controle da União Europeia e, como os números de 2015 foram computados até agosto, ao findar o ano, este número aumentou consideravelmente. O gráfico a seguir ilustra a situação:

Gráfico 2: Mortes de migrantes no mediterrâneo por rota

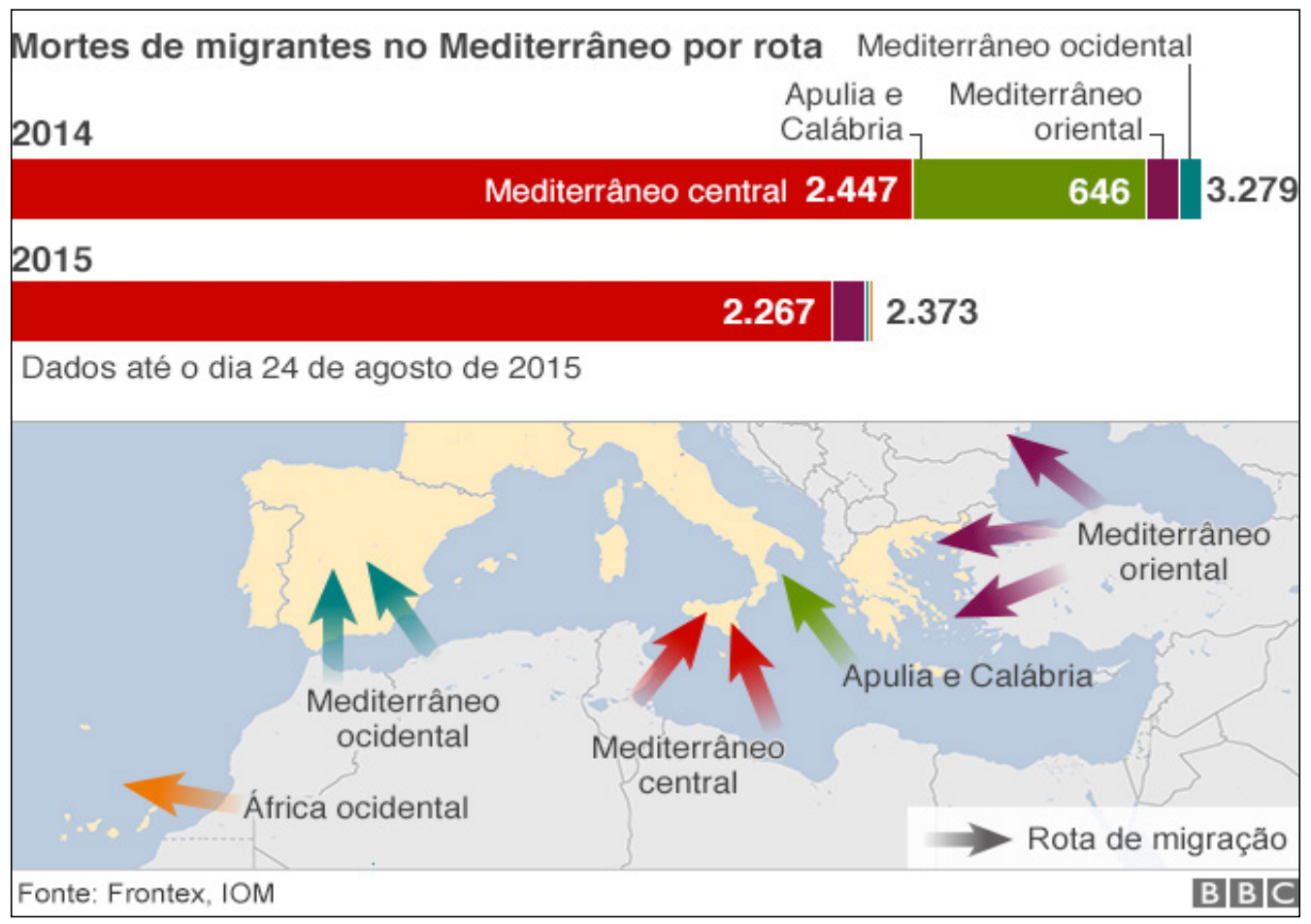

Fonte: BBC Brasil. Refugiados na Europa: a crise em mapas e gráficos. Disponível em: <http:// www.bbc.com/portuguese/noticias/2015/09/150904_graficos_imigracao_europa_rm>. Acesso em: 29 jul 2016. 
Observa-se então que, para os refugiados, a luta pela sobrevivência que se inicia com a fuga de seus países, se estende pela longa jornada aos países de destino e não cessa ao lá chegarem: muitos são os países que fecham as portas e restringem direitos fundamentais de migrantes e refugiados, contrariando frontalmente conceitos básicos do direito internacional, como o princípio do non refoulemant e o princípio da igualdade e não discriminação. A Organização dos Estados Americanos-OEA, em parecer sobre a condição jurídica de imigrantes indocumentados, já havia se pronunciado sobre a obrigação geral dos Estados de respeitar e garantir os direitos humanos, uma vez que esta tem caráter vinculante, independentemente de qualquer circunstância ou consideração, inclusive o status migratório das pessoas (BRASIL, 2014).

O drama dos refugiados e dos imigrantes indocumentados apenas poderá ser tratado em meio a um espírito de verdadeira solidariedade humana para os vitimados de maneira eficaz. Definitivamente, apenas a firme determinação de reconstrução da comunidade internacional com base na solidariedade humana poderá levar à superação de todos estes traumas [...] Impõe-se o desenvolvimento de respostas a novas demandas de proteção, apesar de que não estejam literalmente contempladas nos instrumentos internacionais de proteção do ser humano vigentes (BRASIL, 2014).

Pita (2016, p. 12) assevera que diante do aumento dos movimentos migratórios, sobretudo irregulares (como se observa na Europa), os Estados de forma gradual, incorporam às exigências ao pedido de asilo barreiras migratórias e distintas medidas de controle, mais restritas, na tentativa de dissuadir ou obstruir a possibilidade do pedido. Para o autor, "Essa situação se agravou pela crescente incapacidade dos Estados - inclusive os mais ricos - de estabelecer procedimentos justos, rápidos, efetivos e eficientes para a determinação da condição de refugiado".

Isto tem sido pauta de preocupação por parte do Acnur, que, além da preocupação com os refugiados em geral, vem dedicando grande esforço na construção de estratégias de prevenção contra a violência sofrida por mulheres e crianças. Estas iniciativas são de grande importância, na medida em que este contingente populacional representa ao menos metade dos deslocados em todo mundo e sofre com a violência estatal e não estatal.

\section{Mulheres refugiadas e vulnerabilidade: a dimensão da violência de gênero em situaçóes de refúgio}

Não raro, os países de destino abordam a migração como um problema de segurança nacional, sendo que, especialmente nos últimos anos, tem sido promulgadas uma série de leis para gestão e controle da imigração, passando por

7 O non refoulemant, ou princípio da não devolução, como bem observa Pita (2016) "é a pedra angular da proteção internacional de refugiados, princípio estreitamente vinculado ao de gozar uma série de direitos civis, políticos, econômicos, sociais e culturais". 
cima, inclusive, das normas internacionais que classificam a migração como um direito fundamental. Assim, se evidencia, em tempos de globalização do capitalismo, que a migração humana, mais que um direito, é um privilégio submetido ao acesso a recursos econômicos, sujeito a critérios de discriminação por rações de raça, nacionalidade, sexo, classe social e idade (ORTEGA, 2015, p. 104).

Segundo o ACNUR- Agência das Nações Unidas para Refugiados- as mulheres e crianças representam, ao menos, metade das pessoas deslocadas no mundo, encontrando-se em situação de vulnerabilidade, longe de suas origens, sem a proteção de seu governo, afastadas da família.

Gráfico 3: Pessoas que não permanecem em seu país de origem

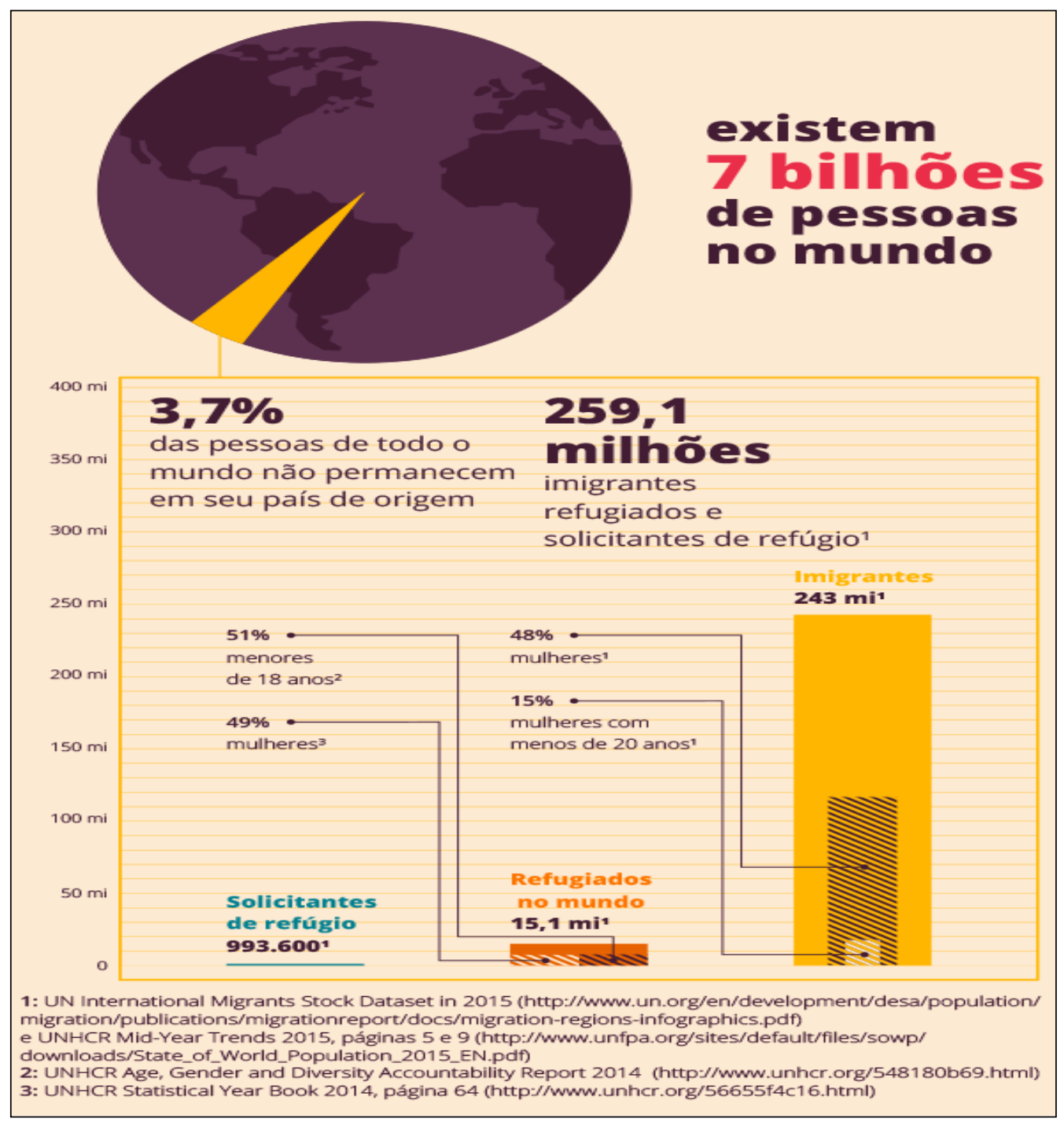

Fonte: SUR. Revista Internacional de Direitos Humanos. Infográficos Migrações e Direitos Humanos. Disponível em: <http://sur.conectas.org/infograficos-migracao/>. Acesso em: 29 jul 2016. 
Na longa jornada em busca de segurança, sofrem com a indiferença oficial, a perseguição e, não raro, com abusos sexuais e a consequente estigmatização por sua condição de mulher refugiada. Os conflitos armados tem sido causa frequente para o grande deslocamento de pessoas, e, para as mulheres, estas situações representam um risco muito maior, uma vez que em muitos casos o estupro tem sido usado como arma de guerra.

De acordo com o Fundo das Nações Unidas para a População - UNFPA, em 2013, as mulheres constituíam 48\% do contingente de migrantes internacionais. No entanto, existem diferenças regionais consideráveis, com as mulheres representando $52 \%$ dos migrantes nas regiões mais desenvolvidas em comparação com $43 \%$ nas regiões menos desenvolvidas. Desde 1990, as regiões menos desenvolvidas tem testemunhado uma queda na proporção de mulheres entre todos os migrantes. Este declínio é principalmente o resultado de um aumento no número de migrantes do sexo masculino na Ásia, onde a percentagem de homens aumentou de 59\% em 1990 para 66\% em 2013, impulsionado pela demanda por trabalhadores migrantes para países produtores de petróleo da Ásia Ocidental.

Em contraste, destinos de migrantes mais tradicionais, como Europa, América Latina e Caribe e na América do Norte, tendem a sediar maiores proporções de mulheres, em parte devido ao envelhecimento da população local, a existência de programas de reunificação familiar e a presença dos trabalhadores domésticos da Ásia e da África.

Para Lisboa (2006), estudos feministas apontam para o que se pode chamar de "feminização das migrações", resultado sobretudo do processo de feminização da pobreza, já que, segundo as Nações Unidas, $70 \%$ dos pobres do mundo são mulheres, o que seguramente tem desencadeado fluxos migratórios internos (nacionais) e externos (internacionais), onde as mulheres migram em busca de melhores condições de vida para si e seus familiares (p. 151/152). Esta situação costuma ser reflexo de

Uma sociedade que trata as pessoas como mercadorias ou apenas como consumidores, que é guiada pelo lucro, que fragmenta e destrói comunidades, que se apropria de bens comuns, que produz vulnerabilidade e insegurança sem valores comuns, se apresenta como uma sociedade infértil para o surgimento de algo tão visceral como a adesão de pessoas aos princípios de uma comunidade estável (GUERRA, 2012, p. 16).

Para Lisboa (2006), os estudos sobre migrações tem ignorado as mulheres, colocando-as em posição de dependência dos homens, tornando-as invisíveis. As diferentes teorias sobre migrações, tanto liberais quanto marxistas, tem se detido no debate sobre as causas dos deslocamentos como sendo de ordem econômica ou política, vinculando-os a "oportunidades de emprego para homens - provedores de família - no modelo capitalista de desenvolvimento, ou reduzem o migrante ao proletário" (p. 152).

Por sua vez, o número de mulheres que migram, sozinhas ou acompanhadas de seus familiares, tem aumentado significativamente nas estatísticas nacionais 
e internacionais, dado o caráter multidimensional dos papéis atribuídos à mulher na família, incluindo sua maior responsabilidade em relação aos filhos, ao sustento da família e o seu deslocamento em função de casamentos (LISBOA, 2006, p. 152).

Para a Comissão das Nações Unidas sobre População e Desenvolvimento - CNPD, além de fatores econômicos, fatores como a busca por uma sociedade mais aberta, a fuga de maus casamentos e de todas as formas de discriminação e violência de gênero e limitadores culturais, também estão entre as razões da migração feminina. "Mulheres e meninas adolescentes estão carregando fardos extraordinários, conforme o agravamento das crises, guerras e desastres naturais deixa um longo rastro de tumulto e destruição" (CNPD, 2015).

Nesse percurso, meninas e mulheres são as que mais sofrem abusos aos seus direitos humanos: violência sexual, tráfico de mulheres, escravidão em locais de trabalho, impossibilidade de contato com a família, são alguns deles. Sofrem, sobretudo, com a dupla face da vitimização: ser mulher e ser migrante. Nesse viés, os sistemas internacionais de proteção aos direitos humanos tem se mostrado insuficientes.

Para Sidney Guerra (2012), existem princípios importantes que podem contribuir para reduzir as complexas relações de desigualdade e individualismo, características da modernidade, como a solidariedade: "o valor ético-jurídico fundamental da solidariedade constitui conditio sine qua non para a inadiável realização dos direitos humanos básicos, para a justa e adequada valorização da condição igual em dignidade e direitos de cada humano".

No mundo globalizado cada vez mais excludente de diferentes grupos sociais (entre estes as mulheres), a solidariedade não parece estar entre os princípios adotados pelas nações, sobretudo as receptoras ocidentais de migrantes. Como lembra Castro (2008, p. 10), "A migração tem relação com o empobrecimento de determinadas classes sociais e a ampliação das desigualdades entre nações [...]", o que, para as mulheres significa, muitas vezes, deixar suas famílias para trás e buscar novas oportunidades em outro continente.

Para Morales (2007, p. 24), as mulheres sempre foram tidas como agentes passivos dos processos migratórios, e não enquanto atores sociais. Para o autor, isto é consequência do estereótipo criado em torno delas como sendo dependentes com ênfase em seu papel de esposa e mãe. De toda sorte, como já referido, as causas das migrações femininas se constituem de múltiplos fatores, que segundo Morales (2007) se não tem sempre o mesmo peso, em alguns casos se apresentam de maneira inter-relacionada como a reunificação familiar, a busca por trabalho, refúgio, asilo, melhores condições econômicas e profissionais, maior independência familiar e ainda, a fuga da violência doméstica (p. 25).

Em razão da distância de suas origens e referências (local de nascimento, moradia, família); da indiferença oficial, com pouca ou nenhuma proteção governamental; dos abusos (sobretudo sexuais) e da estigmatização em razão da condição de mulher e refugiada, são diferentes as dimensões da violência sofrida 
pelas mulheres, que tem influência direta sobre o processo de adaptação a uma nova realidade.

A violência cultural, que se expressa na opressão sofrida dentro do próprio núcleo familiar, o que faz com que as mulheres busquem refúgio em outro país, onde sofrem com dificuldades de adaptação, integração e vivência cotidiana. Faz parte deste contexto também a questão religiosa, de âmbito íntimo e pessoal, muito forte na vida da maioria das mulheres refugiadas, que pode provocar um choque cultural por motivos religiosos: "Há um gap cultural que, por vezes, dificulta a prática cultual" (MARINUCCI, 2014, p. 26).

A violência social, que inclui a manutenção da pobreza; a dificuldade de acesso a serviços públicos; a situação, muitas vezes precária, de moradia; a garantia de direitos e o acesso às políticas públicas. $\mathrm{O}$ acesso a esses serviços, além da dificuldade natural pela condição de "estrangeria", é também prejudicado pela barreira da língua.

A violência psicológica, que inicia com a opressão e perseguição sofrida no país de origem em razão do gênero; o duplo grau de vitimização na condição de mulher e refugiada, o que aumenta o grau de vulnerabilidade (medo, isolamento, dificuldades de integração, estigmatização social etc.).

A violência sexual, talvez a mais perversa de todas, com o uso do estupro como arma de guerra; a exploração sexual e o tráfico a mulheres e meninas para fins sexuais; o assédio no local de trabalho. Nos campos de refugiados, mulheres e crianças são alvos de agressões físicas e de investidas sexuais e, tendo que conviver em um espaço restrito, com um enorme contingente de pessoas sem ocupação, que passaram por diversos traumas, se tornam alvo da violência latente (HINRICHS, 2015). É o momento em que todas as violências se encontram:

O que facilita ainda mais as investidas é o fato de essas mulheres e crianças não disporem de uma rede de contatos sociais, não dominarem o idioma do país, nem saberem onde procurar ajuda. Os agressores podem ser parceiros violentos, companheiros de abrigo invasivos, vigilantes em posse das chaves-mestras, ou colaboradores voluntários que se aproximam de crianças emocionalmente carentes e cometem abuso sexual (HINRICHS, 2015).

A Anistia Internacional, na Campanha "Acabar com a violência sobre as mulheres", afirma que "A violência sobre as mulheres é das mais vastas e persistentes violações de Direitos Humanos, e manifesta-se em diversos contextos: na família, na comunidade, nas instituições estatais, em situações de conflito e pósconflito armado". Ainda, lembra que em todo o mundo, as mulheres são vítimas de violência de várias ordens, simplesmente por serem mulheres e, nesse contexto, uma em cada três mulheres serão vítimas de violência ao longo de suas vidas.

8 Mesmo reconhecendo este gap cultural em relação à religião, o autor chega á conclusão de que mesmo ante às dificuldades culturais, as mulheres acabam reforçando sua fé, participando ativamente de suas denominações religiosas (MARINUCCI, 2014, p. 27). 
Morales (2007) afirma ainda que analisar a migração feminina desde a perspectiva de gênero significa reconhecer que as diferenças entre homens e mulheres não correspondem a uma explicação biológica, mas a uma construção mental da sociedade e as relações de poder estabelecidas (p. 25/26). Tal constatação nos remete à Bourdieu (1989), para quem

Os sistemas simbólicos cumprem a sua função política de instrumentos de imposição ou de legitimação da dominação, que contribuem para assegurar a dominação de uma classe sobre a outra (violência simbólica) [...] para a domesticação dos dominados. As diferentes classes e frações de classes estão envolvidas numa luta propriamente simbólica para imporem a definição do mundo social mais conforme aos seus interesses [...] (p. 11).

Nota-se então que, apesar de um sistema internacional de proteção, da ratificação de diversos tratados pelos diferentes países, os efeitos produzidos ao longo de décadas de vigência destes instrumentos "ainda não foram suficientes para eliminar a discriminação e garantir a igualdade de gênero" (ARAÚJO, 2013, p. 312).

O grande contingente populacional que tem se deslocado de seus países em razão de conflitos armados, do qual faz parte um significativo número de mulheres e meninas, requer da comunidade internacional um esforço maior para acabar com as situações diárias de violência a que estão submetidas. Nesse sentido, as Nações Unidas, através de sua Agência para Refugiados e também do Conselho de Segurança, vem trabalhando com iniciativas para minorar essas situações.

\section{Estratégias do Alto Comissariado das Naçóes Unidas-ACNUR para combate à violência de gênero sofrida por mulheres refugiadas}

As estratégias para combate às diferentes formas de violência sofridas por mulheres e meninas refugiadas, tem sido alvo de atenção da Agência para Refugiados - ACNUR, que tem procurado promover formas de proteção a partir de compromissos assumidos pelo Alto Comissariado, especificamente para atender as especificidades e necessidades de proteção das mulheres refugiadas.

Para tanto, o ACNUR, assumiu cinco compromissos, a serem aplicados especialmente nos campos de refugiados, onde se encontra grande parte das mulheres e meninas refugiadas:

(1) Promover a participação ativa de mulheres refugiadas em funções representativas nos campos de refugiados, alcançando uma taxa de 50\%.

(2) Oferecer registro e documentação individual adequada para todas as mulheres e homens refugiados.

(3) Desenvolver estratégias integrais que combatam a violência sexual e de gênero.

(4) Assegurar a participação de mulheres refugiadas a distribuição e gestão de produtos alimentícios e não alimentícios.

(5) Fornecer assistência sanitária para todas as mulheres e meninas refugiadas (ACNUR, online). 
De acordo com o Alto Comissariado, após dez anos de implementação destes compromissos, foi possível constatar que um terço dos campos de refugiados informaram que mulheres e homens tem representação equitativa nos comitês de gestão dos campos; 93\% das mulheres refugiadas nos campos são registradas individualmente e 51\% recebem a documentação, já em zonas urbanas $91 \%$ das mulheres refugiadas são registradas e à $82 \%$ foi fornecido a documentação; $83 \%$ dos casos de violência sexual baseada em gênero, denunciados nos campos foram encaminhados para receber assistência, já em zonas urbanas, o atendimento de casos reportados chegou a $97 \%$; em boa parte dos campos, pelo menos metade dos representantes para a distribuição alimentícia é composto por mulheres e mais da metade das mulheres e meninas refugiadas recebe assistência sanitária (ACNUR, online).

Além dessas ações, o ACNUR aposta em outras formas de intervenção que beneficiam todos os refugiados, mas tem impacto, sobretudo, na vida das mulheres refugiadas:

Respostas de emergência para situações que exigem resposta imediata, através da mobilização de especialistas para oferecer ajuda emergencial aos civis em deslocamento'; soluções duradouras que visam assegurar direitos e o bem estar dos refugiados através da repatriação voluntária, integração local e reassentamento em um terceiro país; incentivo à promoção de Políticas Públicas que atendam refugiados ou inserção nas políticas existentes; diálogos Regionais com Mulheres e Meninas, aconteceram entre novembro de 2010 e maio de 2011, onde as refugiadas tiveram a oportunidade de expor suas problemáticas, que foram levadas à atenção da comunidade internacional durante a reunião ministerial que aconteceu em dezembro de 2011 em Genebra e campanhas: o ACNUR incentiva e divulga campanhas de combate à violência contra mulheres (16 Dias de Ativismo pelo Fim da Violência contra as Mulheres, que acontece no Brasil todos os anos, por exemplo).

De acordo com o ACNUR,

Como parte de sua estratégia de transversalidade de idade, gênero e diversidade, o ACNUR trabalha com as mulheres refugiadas e deslocadas internas nas Américas com o objetivo de melhorar sua integração nas comunidades de acolhida, tanto em ambientes urbanos quanto rurais, promovendo seu empoderamento e a eliminação da violência sexual e de gênero (online).

Em 2011, o ACNUR lançou o manual "Ação Contra a Violência Sexual e de Gênero: Uma Estratégia Atualizada", no intuito de atualizar as operações de combate à violência sexual de gênero-VSG, não somente de mulheres e meninas,

9 De acordo com a agência, "o ACNUR está pronto para responder a situações novas de emergências que atinjam até 500 mil pessoas. A agência tem capacidade para mobilizar mais de 300 profissionais treinados no prazo de 72 horas. Esses especialistas fazem parte do Time de Resposta Emergencial (ERT, na sigla em inglês). O ACNUR também adotou mecanismos para reunião imediata de recursos financeiros." (ACNUR, online). 
mas também as sofridas por meninos e homens. De acordo com o ACNUR, essa estratégia atualizada busca melhorar a qualidade da proteção fornecida, através do enfoque em seis áreas, que muitas vezes acabam negligenciadas, para que pudessem ser incluídas em uma estratégia de proteção integral:

1. Proteção de crianças vulneráveis à VSG. Crianças deslocadas estão particularmente em risco de se tornarem vítimas da VSG. Além disso, elas enfrentam casos específicos de VSG, incluindo práticas tradicionais nocivas e o abuso e exploração sexual. 2. Abordagem do sexo pela sobrevivência ("survival sex", em inglês) como um mecanismo de enfrentamento em situações de deslocamento. O sexo pela sobrevivência pode ser uma consequência direta de lacunas na assistência ou falhas nos sistemas de registro. 3. Engajar homens e meninos. Os programas relacionados à VSG não envolveram suficientemente homens em atividades de prevenção, o que enfraquece o ambiente de proteção para mulheres e meninas, assim como para homens e meninos. 4. Fornecer ambientes e acesso seguro a energia doméstica e recursos naturais. Muitas mulheres e meninas deslocadas correm o risco de serem estupradas, espancadas ou mortas sempre que buscam água, lenha ou quaisquer outros recursos essenciais. 5. Proteção de gays, lésbicas, bissexuais, transexuais e intersexuais (LGBTI) vulneráveis à VSG. Pessoas do grupo LGBTI podem enfrentar altos índices de discriminação e violência, incluindo a VSG. 6. Proteção de pessoas com deficiência vulneráveis à VSG. Pessoas com deficiência estão frequentemente em risco de sofrerem VSG e são muitas vezes incapazes de acessar os serviços (ACNUR, 2011, p. 5).

O ACNUR entende que a violência sexual e de gênero, envolve situações em que há generalizadas violações a direitos humanos, sendo muitas vezes vinculada a relações desiguais de gênero dentro de comunidades ou abusos de poder. Sendo assim, "Ela pode assumir a forma de violência sexual ou perseguição por parte das autoridades ou pode ser o resultado da discriminação incorporada na legislação, bem como em normas e práticas sociais predominantes". Essa forma de violência pode ser a causa do deslocamento forçado ou ainda, uma parte intolerável do processo de deslocamento (ACNUR, 2011, p. 6).

No ano de 2000, o Conselho de Segurança das Nações Unidas aprovou a Resolução 1325, sobre Mulheres, Paz e Segurança com o objetivo de

proteger os direitos de mulheres e meninas durante conflito armado, combater a impunidade em crimes de gênero, promover a igualdade de gênero em operações de manutenção da paz, e aumentar a participação das mulheres nas atividades de pacificação, antes, durante e depois do conflito armado (FRITZ, 2010, p. 341).

A Resolução faz recomendações aos Estados membro das Nações Unidas para proteção à meninas e mulheres em situação de conflitos, além de pedir que tais ações sejam monitoradas. No entanto, em 2004, o relatório do Secretário Geral sobre Mulheres, Paz e Segurança afirmou que, apesar dos esforços, os problemas ainda eram significativos (FRITZ, 2010, p. 341). Isso fez com que o Conselho de Segurança aprovasse outras resoluções, com vistas a fortalecer os esforços para 
acabar com crimes sexuais em áreas de conflito: 1820 de 2008; 1888 de 2009; 1960 de 2010 e a 2106 de $2013^{10}$.

As Resoluções afirmam que a violência sexual sistemática e usada como arma de guerra, representa uma ameaça à paz e segurança e exige segurança operacional e resposta judicial. Além disso, chamam a atenção para a necessidade de uma investigação consistente e rigorosa, além da repressão aos crimes de violência sexual e a participação das mulheres para respostas de prevenção e proteção (ONU BRASIL, 2013).

O ACNUR reconhece a importância das resoluções do Conselho de Segurança, o que demonstra a importância do tema em âmbito internacional, ao mesmo tempo em que identifica a necessidade de construção de novas estratégias (ACNUR, 2011, p. 5).

Percebe-se então, os esforços do Alto Comissariado das Nações Unidas para Refugiados-ACNUR na tentativa de combater a violência de gênero, sobretudo a violência sexual, que, em certa medida, afeta todas as dimensões da vida de meninas e mulheres refugiadas, por seu caráter brutal de violação aos direitos humanos dessa população. Por outro lado, é possível constatar que, diante do fluxo cada vez maior de pessoas deslocadas em razão de conflitos armados, essas violações estão longe de acabar.

\section{Conclusóes}

O mundo hoje se encontra diante de uma realidade brutal: milhares de pessoas são diariamente forçadas a deixar suas casas, suas vidas, sua terra, para fugir de perseguições e rumar para uma vida melhor, longe da violência e da pobreza. Mas, alguém poderia lembrar: a migração sempre existiu, o que é fato. A diferença está no volume desses deslocamentos (mesmo as migrações representando apenas $3,7 \%$ da população mundial em movimento, o fato é que os fluxos migratórios aumentaram significativamente nos últimos anos) e nas crises humanitárias que os tem provocado.

No campo da proteção às mulheres, encontram-se uma série de instrumentos internacionais de proteção, que, quando referendados por diferentes países, passam a integrar o arcabouço jurídico nacional. O que se tem constatado é que, se para as mulheres nacionais estes instrumentos de proteção são insuficientes para garantia de seus direitos humanos, para as "estrangeiras", este cenário é ainda mais perturbador:

10 O texto completo das Resoluções pode ser encontrado online: Resolução 2106 (2013): < http:// www.un.org/ga/search/view_doc.asp?symbol=S/RES/2106(2013)>; $\quad$ Resolução 1960 (2010): <http://www.securitycouncilreport.org/atf/cf/\%7B65BFCF9B-6D27-4E9C-8CD3CF6E4FF96FF9\%7D/WPS\%20SRES\%201960.pdf>; Resolução 1888 (2009): <http:/ /www. securitycouncilreport.org/atf/cf/\%7B65BFCF9B-6D27-4E9C-8CD3-CF6E4FF96FF9\%7D/ WPS\%20SRES\%201888.pdf>; Resolução 1820 (2008): <http://www.itamaraty.gov.br/ images/ed_pazeseg/Mulheres_paz/1820-2008-PT.pdf>. 
vitimadas duas vezes, como mulheres e como migrantes, sobretudo refugiadas, ficam à mercê de sistemas de proteção falhos ou ainda caem na invisibilidade.

Nesse contexto, a violência sofrida por mulheres refugiadas tem várias dimensões, nem sempre alcançadas pelas instituições responsáveis por sua proteção, mostrando que os esforços tem sido insuficiente para sanar essas violências. Diante do aumento de conflitos armados que geram um grande número de refugiados, mulheres e meninas são vítimas em potencial de uma série de violências, de caráter social, cultural, psíquico e sexual. Esta última acaba por afetar todas as dimensões da vida das refugiadas, uma vez que o medo de sofrer abusos de caráter sexual, as afasta ou, ao menos, dificulta sua inserção social plena e a construção de uma vida da qual os abusos não sejam uma realidade.

Portanto, apesar dos esforços para combater a violência contra meninas e mulheres refugiadas, ainda há muito a evoluir, inclusive, no processo de aceitação social dos imigrantes e refugiados, com a desmistificação do imigrante que traz violência, que rouba empregos, que é foragido (refugiado=foragido). Esses discursos apenas disseminam intolerância e preconceito, e fragilizam ainda mais quem já está em uma condição extremamente frágil. Estado e sociedade devem trabalhar juntos nesse processo e as ações de organismos internacionais como o ACNUR e o Conselho de Segurança das Nações Unidas devem focar em resultados concretos: o fim da violência de gênero contra meninas e mulheres refugiadas.

\section{REFERÊNCIAS}

ACNUR. Alto Comissariado das Nações Unidas para Refugiados. Ação contra a violência sexual e de gênero: uma estratégia atualizada. ACNUR: Divisão de Proteção Internacional, 2011. Disponível em: <http://www.acnur.org/fileadmin/scripts/doc. php?file=fileadmin/Documentos/portugues/Publicacoes/2012/Acao_contra_a_ violencia_sexual_e_de_genero>. Acesso em: 29 jul. 2016.

. Alto Comissariado das Nações Unidas para Refugiados. Mulheres refugiadas. Disponível em: <http://www.acnur.org/portugues/quem-ajudamos/dmr-20110/>. Acesso em: 29 jul. 2016.

- Alto Comissariado das Nações Unidas para Refugiados. O que é a Convenção de 1951? Disponível em: < http://www.acnur.org/portugues/informacao-geral/o-que-ea-convencao-de-1951/>. Acesso em 29 jul. 2016.

- Alto Comissariado das Nações Unidas para Refugiados. Os $\mathbf{5}$ compromissos

do ACNUR com mulheres refugiadas. Disponível em: < http://www.acnur.org/ portugues/quem-ajudamos/dmr-20110/os-5-compromissos-do-acnur-com-mulheresrefugiadas/>. Acesso em 29 jul. 2016.

- Alto Comissariado das Nações Unidas para Refugiados. Preparando respostas

para as emergências. Disponível em: $<$ http://www.acnur.org/portugues/quemajudamos/resposta-a-emergencias/>. Acesso em: 29 jul. 2016. 
Alto Comissariado das Nações Unidas para Refugiados. Mulheres refugiadas que se deslocam pela Europa estão correndo riscos, afirma a ONU. Publicado em 26 jan. 2016. Disponível em: <http://www.acnur.org/portugues/noticias/noticia/ mulheres-refugiadas-que-se-deslocam-pela-europa-estao-correndo-riscos-afirma-a-onu $/>$. Acesso em 29 jul. 2016.

ANISTIA INTERNACIONAL PORTUGAL. Acabar com a violência sobre as mulheres. Disponível em: <http://www.amnistia-internacional.pt/index. php?option $=$ com_content\&view $=$ article\&id $=42 \& I t e m i d=53>$. Acesso em 29 jul. 2016.

ARAÚJO, Marinella Machado. A proteção das mulheres: direitos com força normativa ou simbólica? In: JUBILUT, Liliana L. (org.). Direito à diferença: aspectos de proteção específica às minorias e aos grupos vulneráveis. São Paulo: Saraiva: 2013.

BBC BRASIL. Refugiados na Europa: a crise em mapas e gráficos. Disponível em: <http://www.bbc.com/portuguese/noticias/2015/09/150904_graficos_imigracao_ europa_rm>. Acesso em 29 jul. 2016.

BRASIL. Secretaria Nacional de Justiça, Comissão de Anistia. Jurisprudência da corte Interamericana de Direitos Humanos: migração, refúgio e apátridas. Tradução da Corte Interamericana de Direitos Humanos. Brasília : Ministério da Justiça, 2014.

BOURDIEU, Pierre. O Poder Simbólico. Tradução de Fernando Tomaz. Rio de Janeiro: Bertrand Brasil, 1989.

CASTRO, Mary Garcia. Migrações Internacionais e Direitos Humanos e o aporte do reconhecimento. In: In: REHMU- Revista Interdisciplinar da Mobilidade Humana. Ano XVI, n. 31, 2008. Disponível em: <http:/ /www.csem.org.br/remhu/index.php/ remhu/article/view/92/84>. Acesso em: 29 jul. 2016.

CNPD. Comissão das Nações Unidas sobre População e Desenvolvimento. Situação da População Mundial 2015. Disponível em: <http:/ /www.unfpa.org.br/Arquivos/ sumario_swop2015.pdf>. Acesso em 29 jul. 2016.

FÓRUM. Mulheres refugiadas relatam estupro em troca de abrigo na Europa. Publicado em 27 jan. 2016. Disponível em: <http:/ /www.revistaforum.com. br/2016/01/27/mulheres-refugiadas-relatam-estupro-em-troca-de-abrigo-na-europa/>. Acesso em 29 jul. 2016.

FRITZ, Jan Marie. Mulheres, Resolução do Conselho de Segurança das Nações Unidas 1325 e a necessidade de planos nacionais. In: Sociologias. Porto Alegre, ano 12, no 23 , jan./abr. 2010, p. 340-353. Disponível em: < http://www.scielo.br/pdf/soc/n23/12.pdf>. Acesso em: 29 jul. 2016.

G1. Refugiadas sofrem violência sexual em êxodo, diz Anistia Internacional.

Publicado em 18 jan. 2016. Disponível em: <http://g1.globo.com/mundo/ noticia/2016/01/refugiadas-sofrem-violencia-sexual-em-exodo-diz-anistia-internacional. html>. Acesso em: 29 jul. 2016.

GUERRA, Sidney. Direitos Humanos e Cidadania. São Paulo: Atlas: 2012. 
HINRICHS, Beate. In: DEUTSCHE WELLE. Opinião: mulheres e crianças sofrem violência em abrigos de refugiados. Publicado em 11 out 2015. Disponível em: $<$ http://www.dw.com/pt/opini\% $\%$ C3\%A3o-mulheres-e-crian $\%$ C3\%A7as-sofremviol\% $\%$ C3\%AAncia-em-abrigos-de-refugiados/a-18775811>. Acesso em 29 jul. 2016.

IMDH. Instituto Migrações e Direitos Humanos. Migrantes: quem são? Publicado em 22 jan 2014. Disponível em: <http://www.migrante.org.br/index.php/migrantes-quemsao >. Acesso em: 29 jul. 2016.

JORNAL MULIER. Mulheres e crianças já são 2/3 dos refugiados e representam grupo mais vulnerável à violência. Publicado em 27 jun. 2016. Disponível em: <http://jornalmulier.com.br/mulheres-e-criancas-ja-sao-23-dos-refugiados-erepresentam-grupo-mais-vulneravel-a-violencia/>. Acesso em 29 jul. 2016.

LEVY, Tatiana Salem. A chave de casa. São Paulo: Record, 2007.

LIPPSTEIN, Daniela; GOMES, Daniela. A proteção político-jurídica do refugiado ambiental. In: Revista Direito em Debate. Revista do Departamento de Ciências Jurídicas e Sociais da Unijuí. Ano XXII, n 40, jul.-dez. 2013, p. 155-192. Ijuí: Unijuí, 2013.

LISBOA, Teresa Kleba. Gênero e Migrações: trajetórias globais, trajetórias locais de trabalhadoras domésticas. In: REHMU- Revista Interdisciplinar da Mobilidade Humana. Ano XIV, n. 26 e 27 - 2006. Disponível em: <http:/ /www.csem.org.br/ remhu/index.php/remhu>. Acesso em 29 jul. 2016.

MARINUCCI, Roberto. A dimensão religiosa. P. 25-27. In: CSEM. Centro Scalabriniano de Estudos Migratórios. Mulher Migrante: agente de resistência e transformação. Brasília: CSEM, 2014.

MORALES, Ofelia Woo. La migración de las mujeres: um proyecto individual o familiar? In: REHMU- Revista Interdisciplinar da Mobilidade Humana. Ano XV, n. 29, 2007. Disponível em: <http://www.csem.org.br/remhu/index.php/remhu/article/ view/56/48>. Acesso em 29 jul. 2016.

ONU BRASIL. Nações Unidas no Brasil. Conselho de Segurança da ONU fortalece esforços pelo fim da violência sexual em conflitos. Disponível em: < https:/ / nacoesunidas.org/conselho-de-seguranca-da-onu-fortalece-esforcos-pelo-fim-daviolencia-sexual-em-conflitos/>. Acesso em: 29 jul. 2016.

ONU BRASIL. Nações Unidas no Brasil. Número de migrantes internacionais chega a cerca de 244 milhões, revela ONU. Publicado em 13 jan 2016. Disponível em: $<$ https:/ / nacoesunidas.org/ numero-de-migrantes-internacionais-chega-a-cerca-de-244milhoes-revela-onu/>. Acesso em: 29 jul. 2016.

ORTEGA, Ana. La migración de mujeres hondureñas y la crisis de los cuidados. In: Revista Nueva Sociedad. N. 256, marzo-abril 2015. Disponível em: <http//:www.nuso.org>. Acesso em 29 jul. 2016.

PRAGMATISMO POLÍTICO. Mulheres e crianças são estupradas como forma de “pagar” entrada na Europa. Publicado em 28 jan. 2016. Disponível em: < http:/ /www. 
pragmatismopolitico.com.br/2016/01/mulheres-e-criancas-sao-estupradas-como-formade-pagar-entrada-na-europa.html>. Acesso em: 29 jul. 2016.

PITA, Agni Castro. Direitos Humanos e Direito Internacional dos Refugiados. In: GEDIEL, José Antônio Peres; GODOY, Gabriel Gualano de (org.). Refúgio e Hospitalidade. Curitiba: Kayrós Edições, 2016.

WINCKLER, Silvana. A condição jurídica atual dos imigrantes no cenário internacional à luz do pensamento da Hannah Arendt. In: AGUIAR, Odilio Alves (et al). Origens do Totalitarismo 50 anos depois. Rio de Janeiro: Relume Dumará; Fortaleza: Secretaria de Cultura de Desporto, 2001. 